\title{
Multicriteria Evaluaton of Efficiency in Fish Processing
}

\author{
Karlis Dreimanis $^{1 *}$, Zane Indzere ${ }^{2}$, Dagnija Blumberga ${ }^{3}$, Vaida Šerevičiené ${ }^{4}$ \\ ${ }^{1-3}$ Institute of Energy Systems and Environment, the Faculty of Power and Electrical Engineering, \\ Riga Technical University, Riga, Latvia \\ ${ }^{4}$ Research Institute of Environmental Protection, Faculty of Environmental Engineering, \\ Vilnius Gediminas Technical University, Vilnius, Lithuania
}

Received 02 March 2020; accepted 24 March 2020

\begin{abstract}
EU countries have agreed on GREEN DEAL and have committed to achieve carbon neutrality by 2050 . Very important role for achieving the goal is playing production and manufacturing industry. This article is devoted to fish production industry, which is as subdivision of food production industry. During past decades the amount of fish caught has increased multiple times. Fishing industry nowadays is being strongly regulated and monitored by various institutions including. Which sets environmental legislation for controlling and improving industries impact (energy efficiency, pollution, waste) on the habitat and environment. For EU to make right decisions on how the member states could develop their fish production industry, it is necessary to have overall evaluation which includes the development opportunities. The efficiency of the fish production company characterizes the amount of resources used, as well as energy efficiency, water usage, the possibility to implement of circular economy, and other criteria which must be evaluated from the perspective if environmental, engineering, economic and social aspects.

The fish production company analysis in this article are analysed using Data envelopement analysis (DEA) multicriteria analysis. First results show that fish manufacturers must pay attention to the technological processes in order to move towards carbon neutral society.
\end{abstract}

Keywords: fish production industry, data envelopement analysis, technological process.

\section{Introduction}

Fishing and fish production industry, since early days, has been one of the main and most important subdivision of the food production industry. During past decades due to the development of technologies and increase in production demand, the amount of fish caught per year has increased multiple times (CSP, n. d.).

The efficiency of the fish production company characterizes the amount of resources used, as well as energy efficiency, water usage, the possibility to implement of circular economy, and other criteria which must be evaluated from the perspective if environmental, engineering, economic and social aspects. The production costs, such as labour costs, resource and delivery costs are directly impacted by energy efficiency.

EU countries have agreed on GREEN DEAL and have committed to achieve carbon neutrality by 2050. Very important role for achieving the goal is playing production and manufacturing industry.

In order for the EU legislation to be effective and implement planned changes it is important that the starting information and data about the problem, which is planned to be regulated, is correct.

For EU to make right decisions on how the member states could develop their fish production industry, it is necessary to have overall evaluation which includes the development opportunities

Data gathering, availability and analysis are very important to evaluate the existing situation and modeling the planned changes, because it allows to better explain and reason the need for change and setting future goals.

The lack of data and false data may impact the evaluation of the current situation and therefore lead to decisions which may not be the most effective.

The fish production company analysis in this article are analyzed using DEA (data envelopment analysis) multicriteria analysis.

\section{General regulations}

The manufacturing process of fish products varies, depending of the specifics of the final product. Various factors must be considered when choosing the right equipment which enables the production process. For it the be efficient the most

*Corresponding author. E-mail: karlis.dreimanis12@gmail.com 
cost-effective machinery and processes, approaches and product usage should be chosen. A brief description of a simple technological process is show below.

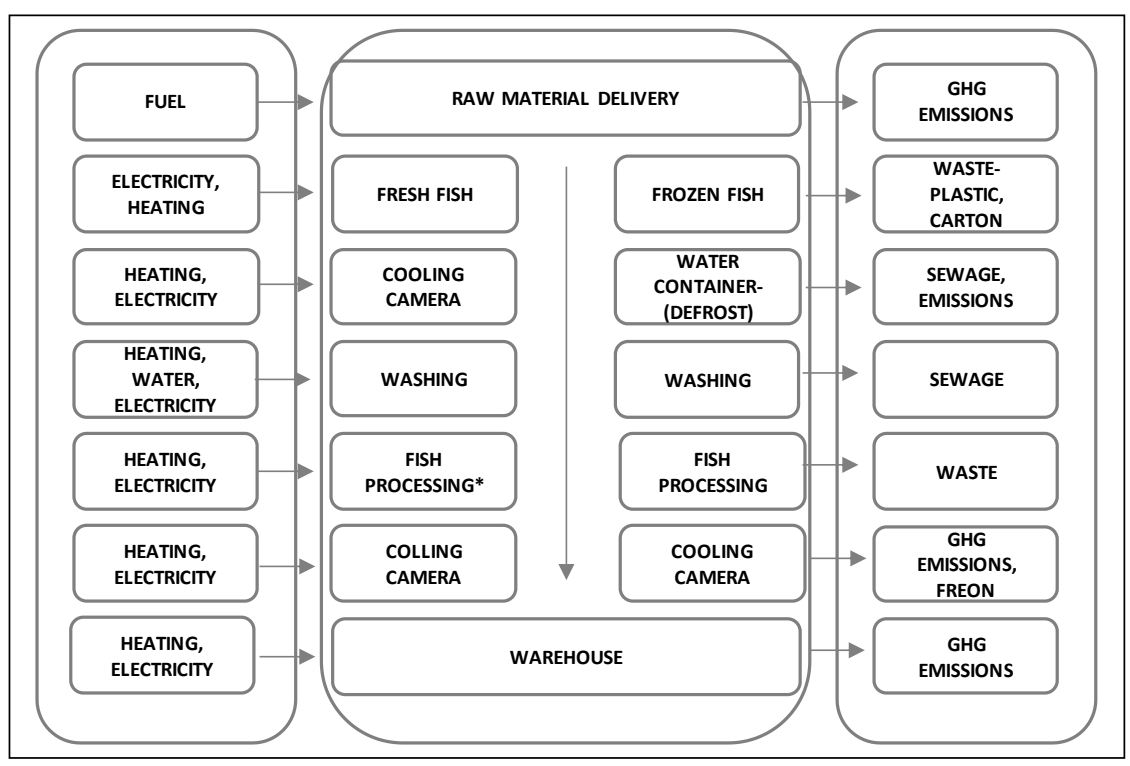

Figure 1. Technological process of canned fish processing

This technological process does not include the fish product sterilization stage of cans which consumes rather large amount of energy and is important for product to meet the expiry time. This thermal process which can last from 5 to 20 minutes at a temperature around 120 degrees Celsius is important to eliminate that spoilage bacteria spores to the tolerance level (Bremner, 2002). This process requires custom made equipment which is set for specific product. The cost of such machinery varies from 5-50 thousand dollars, depending of the modification. The water supply is necessary to produce the steam.

For the evaluation of the technological process and sterilization specifically the multi criteria analysis (MCA) and data envelopment analysis (DEA) method is used to try and develop most efficient sterilization method criteria.

\section{Method}

Data envelopment analysis (DEA) is used to determine the most efficient solution for the chosen models of technological (sterilization) methods. DEA is a linear programming methodology and is used to measure decision making units (DMU) which allows to set boundaries for the various parameters analyzed (Yilmaz \& Yurdusev, 2011). The model consists of DMU matrix where the limits, values and inputs and outputs are defined. The DEA models are designed in a way that they can determine the efficiency input or output oriented. The output-oriented model refers to the capacity of DMU to achieve the maximum volume of the production volume, but the input oriented model refers to maintain the same capacity of production using minimum inputs (Yilmaz \& Yurdusev, 2011).

For defining the DMU matrix for calculation of the most efficient sterilization method, a scenario shall be chosen in which the most efficient method will be determined. The DMU matrix will be designed for a sterilization method which will have to enable the 120 degrees Celsius for 10 minutes. Various types of sterilization equipment will be tested taking into account their energy used, work capacity - time (output) to fulfill the scenario and criteria, as showed in Table 1. Input will be defined as power, manpower needed to operate, the amount of product sterilized in the time allocated. Each input will be assigned a value (weight) so that it is know which criteria is most valuable and important.

Table 1. Technological process of canned fish processing

\begin{tabular}{|c|c|c|c|c|c|}
\hline Method & $\begin{array}{c}\text { Water } \\
\text { consumption, } \\
\mathrm{M}^{3} / \mathrm{t}_{\text {fish }}\end{array}$ & $\begin{array}{c}\text { Electricity } \\
\text { consumption, } \\
\mathrm{MWh} / \mathrm{t}_{\text {fish }}\end{array}$ & $\begin{array}{c}\mathrm{CO}_{2} \text { Emissions, } \\
\mathrm{TCO}_{2} / \mathrm{t}_{\text {fish }}\end{array}$ & $\begin{array}{c}\text { Equipment } \\
\text { efficiency }\end{array}$ & $\begin{array}{c}\text { Internal costs, } \\
\text { EUR }\end{array}$ \\
\hline Water spray retort & & & & & \\
\hline Water immersion retort & & & & & \\
\hline Steam and Air retort & & & & & \\
\hline Steam retort & & & & & \\
\hline
\end{tabular}


All DEA models allow unrestricted weight flexibility in determining the efficiency scores DMUs (Yilmaz \& Yurdusev, 2011).

This type of analysis helps to compare the alternatives of the possibilities and also evaluate their performance and efficiency.

$$
\text { The efficiency }=\frac{\text { weighted } \text { sum of outputs }}{\text { weighted sum of inputs }}
$$

Assumption is made that number of MDU are defined with $\mathrm{m}$ inputs and s outputs. The relative efficiency scenario for DMU p is solved by the CCR model (Charnes et al., 1978) and (Yilmaz \& Yurdusev, 2011).

$$
\begin{gathered}
\max \frac{\sum_{k=1}^{s} U k Y k p}{\sum_{j=1}^{m} V j X j p} ; \\
\text { s.t. } \frac{\sum_{k=1}^{s} U k Y k i}{\sum_{j=1}^{m} V j X j i} \leq 1 ; \quad i=1,2, \ldots, n ; \quad U_{k}, V_{j} \geq 0 ; \quad k=1,2, \ldots s ; \quad j=1,2, \ldots, m,
\end{gathered}
$$

where: Yki is the amount of $k$ produces by the DMU $i$; Xji is the amount of input $\mathrm{j}$ utilized bu the DMU $i$; $U_{k}$ is the weight given to output $k ; V j$ is the weight given by input $j$.

The function equation is solved by converting to linear program in the following way:

$$
\begin{gathered}
\operatorname{Max} \sum_{k=1}^{s} U k Y k p ; \\
\text { s.t. } \sum_{j=1}^{m} \operatorname{VjXjp}=1 ; \quad \sum_{k=1}^{s} U k Y k i-\sum_{j=1}^{m} V j X j i \leq 0 ; \\
i=1,2, \ldots, n ; \\
U_{k}, V_{j} \geq 0 ; \quad k=1,2, \ldots m ; \quad j=1,2, \ldots, m .
\end{gathered}
$$

Equation (3) is solved $\mathrm{n}$ times to identify the relative efficiency scores in DMU (Yilmaz \& Yurdusev, 2011). These allow to construct the efficiency frontier. The efficiency is assumed when the score is 1 , and everything below is assumed to be inefficient.

The visual graph of alternative frontier helps the decision maker easier understand the alternatives which of the DMU are efficient and which need improvement and maximization to become efficient.

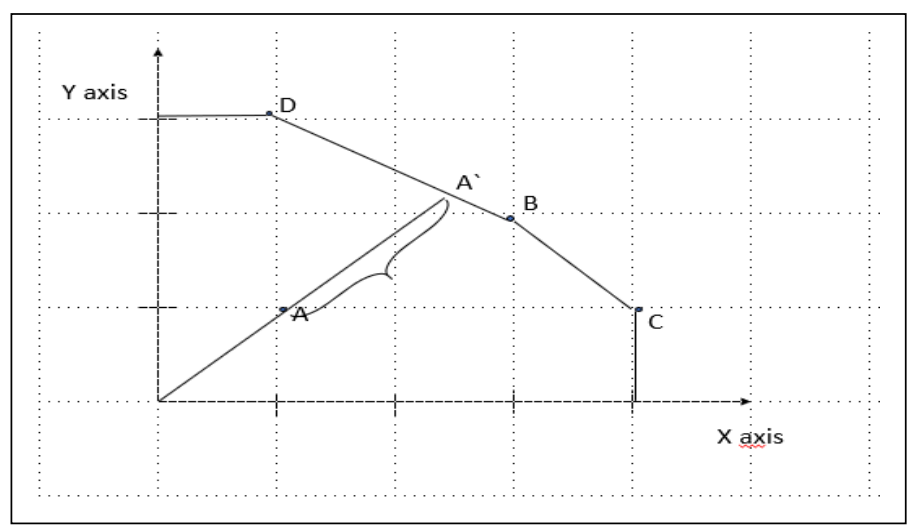

Figure 2. DEA efficiency frontier

Figure 2 shows schematic overview of the DMU output- oriented model. The DMU points being plotting of the $x$ and $y$ axis, which values are defined by Eq. (1). In this way the efficiency frontier is determined. The efficiency frontier allows to see the DMU and which is not efficient. In this case Value A is inefficient and need value AA to become efficient.

\section{Results}

Results are expected to show the best solution for tested DMU inputs and outputs. Also show the efficiency that must be achieved by the least efficient solutions to be competitive and reach the efficiency line. The developed model is 
expected to help the fish processing companies find most suitable solutions for the technological processes and by doing so decrease the operational costs.

\section{Conclusions}

The conclusions will be drawn after the evaluation of the models tested for the operational processes, sterilization methods. The final result will allow to estimate the most efficient model and evaluate the improvements needed for compared options which were not proved to be the most efficient at the time.

\section{References}

Bremner, H. A. (Ed.). (2002). Safety and quality issues in fish processing. L. Ababouch HACCP in the fish cleaning industry. Woodhead Publishing Limited. https://doi.org/10.1533/9781855736788

Central Statistical Bureau of Latvia. (2019). The stats about fish caught. https://www.csb.gov.lv/lv/statistika/statistikastemas/lauksaimnieciba/zivsaimnieciba/meklet-tema/443-nozvejotas-zivis-statistikai100

Charnes, A., Cooper, W. W., \& Rhodes, E. (1978). Measuring the efficiency of the decision making units. European Journal of Operational Research, 2(6), 429-444. https://doi.org/10.1016/0377-2217(78)90138-8

Yilmaz, B., \& Yurdusev, M. A. (2001). Mathematical and Computational Applications, 16(3), 669-679. https://doi.org/10.3390/mca16030669 